This item was submitted to Loughborough's Research Repository by the author.

Items in Figshare are protected by copyright, with all rights reserved, unless otherwise indicated.

\title{
Enlivening evidence-based policy through embodiment and emotions
}

PLEASE CITE THE PUBLISHED VERSION

http://dx.doi.org/10.1080/21582041.2013.770909

\section{PUBLISHER}

Taylor and Francis / @ Academy of Social Sciences

\section{VERSION}

AM (Accepted Manuscript)

\section{PUBLISHER STATEMENT}

This work is made available according to the conditions of the Creative Commons Attribution-NonCommercialNoDerivatives 4.0 International (CC BY-NC-ND 4.0) licence. Full details of this licence are available at: https://creativecommons.org/licenses/by-nc-nd/4.0/

\section{LICENCE}

CC BY-NC-ND 4.0

\section{REPOSITORY RECORD}

Hardill, Irene, and Sarah Mills. 2019. "Enlivening Evidence-based Policy Through Embodiment and Emotions". figshare. https://hdl.handle.net/2134/18035. 


\section{Enlivening evidence-based policy through embodiment and emotions Irene Hardill , and Sarah Mills+}

\section{Department of Social Sciences}

\section{Northumbria University}

\section{+ Department of Geography}

\section{Loughborough University}

\section{Abstract}

Evidence-based policy and practice tends to operate on a belief that knowledge is obtained through objective observation and reasoning, leading to 'rational decision-making'. But the work of producing such knowledge is typically more 'messy', more iterative and more nonlinear; features of the knowledge production process only made more pronounced by imperatives such as co-production. Just over a decade ago Smith and Anderson traced out a position countervailing to that of the predominant - yet, at that stage, only tentative - 'policy (re)turn' in human geography and set about charting a new course of research, variously promoting and encouraging a more enthusiastic laying bare of the researcher's positionalities and emotional sensitivities. In this paper we wish to briefly reassess the 'emotional turn', via a case study centring on the New Dynamics of Ageing (NDA) research programme to highlight the challenges of translating emotions into a policy making environment. In our project we examined the ways in which the materialities of ICT (and new technology more broadly) are embedded in everyday life. How people feel, their emotional sensitivities, towards the use of information and communication technologies (ICTs) we argue is crucial 
for understanding the potential impact of the current public policy thrust to move to the online delivery of public services (or egovernment). Adding emotional sensitivities in the body of knowledge when in dialogue with policy makers we suggest enriches evidence based policy that centres on behaviour change.

\section{Keywords}

Embodiment, emotions, knowledge 


\section{Introduction}

Evidence-based policy and practice operates on a belief that knowledge is obtained through objective observation and reasoning. But the work of producing such knowledge is typically more 'messy', more iterative and more non-linear; features of the knowledge production process only made more pronounced by the rhetoric of knowledge exchange and collaborative working (Bannister and O’Sullivan, this issue). These interactions, like so many others, are susceptible to the same emotionally-fused behaviours as other practices; yet rather than being figured as key moments to be fed back, these emotional 'events' are often distorted or, worse, suppressed in the resulting dialogue with policy makers. In 2001, Smith and Anderson traced out a position countervailing to that of the predominant - yet, at that stage, only tentative - 'policy (re)turn' in human geography. Encouraging a research approach more cognisant of and sensitive to the ways in which "the human world is constructed and lived through emotions" (p. 7), Smith and Anderson set about charting a new course of research, variously promoting and encouraging a more enthusiastic laying bare of the researcher's positionalities and emotional sensitivities. At the same time as Smith and Anderson were writing in 2001, former UK Prime Minister Tony Blair was establishing the Delivery Unit, a key philosophy behind it being that, 'numbers are important but not enough: citizens have to see and feel the difference' (Barber, 2007, p. 370). So while hard evidence was a guiding star in the pursuit of evidence based policy under New Labour, the establishment of the Delivery Unit also indicated that there was recognition that policy making could in part be fused with emotion.

In this paper we aim to contribute to this special issue on knowledge mobilisation by highlighting embodied knowledge and the promise of non-representational theory with 
reference to translating emotion in a policy making environment. Evidence-based policy is a key area where an awareness of how emotional relations shape society and space is important especially in times of economic austerity, when citizens are being asked in a multitude of ways to change their behaviour. Specifically we chronicle developments in the field of emotional geographies - and beyond - since Smith and Anderson's groundbreaking paper, before flagging some of the difficulties caught up in the appropriate channelling and representation of these emotional events, by means of a case study centring on the first author's involvement in 'Sustaining IT use by older people to promote autonomy and independence (Sus-IT) (RES-353-25-0008), a research project funded in the UK by the New Dynamics of Ageing Programme (NDA). Specifically we link emotional and embodied complexities relating to the Information and Communication Technology (ICT) ${ }^{\mathrm{i}}$ use of older people to the current policy thrust for the online delivery of public services. We argue that emotional sensitivities form a key component in the body of knowledge and could make policy making more effective. After this introduction the paper is divided into three further sections. Section two examines the concepts of emotion and affect and nonrepresentational theory's place in their theorisation. This is followed by an analysis of the Sus-IT project. The final section is the conclusion.

\section{Emotions, embodiment and affect}

The human world is constructed and lived through emotions. For researchers to therefore silence emotion inevitably produces an incomplete understanding of society and space. This claim lies at the heart of 'emotional geographies' - a wide-ranging and invigorated subdiscipline that emerged from Anderson and Smith’s aforementioned paper (see also Davidson and Milligan, 2004; Davidson et al., 2005). In this section, we provide a brief overview of how the engagement with emotions, as well as related concepts of embodiment and affect, 
has shaped a number of useful research avenues within contemporary human geography. Kay Anderson and Susan Smith argued that "the gendered basis of knowledge production is probably a key reason why the emotions have been banished from social science and most other critical commentary for so long. This marginalisation of emotion has been part of a gender politics of research in which detachment, objectivity and rationality have been valued... while engagement, subjectivity, passion and desire have been devalued, and frequently feminized.” (2001, p. 7). However, our rational thoughts and experiences are framed by emotions and are shaped by so many things beyond representation - by "alwaysalready-all-sorts-going-on...” (Horton and Kraftl, 2006, p. 259). Indeed, Owain Jones argues that "these emotional spatialities of becoming, the transactions of body(ies), space(s), mind(s), feeling(s) in the unfolding of life-in-the-now, are the very stuff of life we should be concerned with when trying to understand how people make sense of/practice the world" (2005, p. 206, our emphasis). In this paper we too understand emotions as context specific (time, place and setting) and give particular emphasis to the emotional context of engaging with digital technologies and how this unfolds as part of 'life-in-the-now'. Furthermore, there are interesting parallels here with the emotional spatialities of how research and researchers in and on 'peripheral' and 'marginal' areas of research are considered by the wider social science academy. Many of the issues and processes of marginalisation are similar and just as restricting.

There are subsequently two (but by no means the only) important elements to debates on 'emotion' that need to be considered by social scientists. On the one hand, taking emotions seriously helps researchers to explore the social relations and everyday (emotional) lives of research participants (Bennett, 2004; Pini et al., 2010). This necessarily involves a recentering of the body as a form of lived experience - to consider the emotional and embodied 
'goings-on' in our lives (Horton and Kraftl, 2006; Thrift, 2004). On the other hand, there is an important need to acknowledge and critically assess the position of the researcher as an emotional and embodied being (Bondi, 2005). Whilst reflexivity is now a well-rehearsed (but still vitally important) element of research in the social sciences, the emotional impulses and often political motivations that shape research design and relationships with participants (Askins, 2009; Brown and Pickerill, 2009), as well as the embodied ways we 'do' research (Longhurst et al., 2008), have only recently been considered.

An important and related concept when discussing emotion and embodiment is affect (McCormack, 2003; Thrift, 2004) - the 'always emergent' embodied practices that valorise the processes which operate before conscious thought - a "realm of potential” (McCormack, 2003, p. 495). Affect can therefore be used to develop accounts of the emotions of everyday life and embodied practices and has come to characterise 'non-representational theory' (NRT) (Anderson and Harrison, 2010). Whilst there are methodological challenges in "how to capture the often evasive nature of affect” (Rose et al. 2010, p. 340) - indeed emotions and feelings are often difficult to articulate coherently - a series of more performative and nonrepresentational methodologies can help to go beyond "the proforma social science treatment of interview transcripts” (Lorimer, 2005, p. 87) and challenge the primacy of the decontextualised interview (Sin, 2003). These include photo-diaries (Latham, 2003), sensory ethnography (Pink, 2009) and participatory video methods (Simpson, 2011), creating new possibilities to embrace context, capture emotional experiences and study embodied practices. Indeed, Hayden Lorimer has suggested that in his experience, "NRT works best as a background hum, asking questions of style, form, technique and method, and ushering in experimental kinds of response” (2008, p. 556). 
It is important to note here that there are similarities and differences between 'affect' and 'emotion', as well as critical debates surrounding NRT (Anderson and Harrison, 2006; Pile, 2010; Thien, 2005). It is not the aim of this paper to contribute to these specific debates, but rather, our focus here is to stress the importance of the emotional and/or the affective in social science research and to argue that evidence-based policy is one area where an awareness of how emotional/affective relations shape society could be productive, using the example of understanding ICT usage and the online delivery of public services.

In the following section we critically reflect on the Sus-IT research project, highlighting how the emotions of those enrolled in the project's delivery affected their involvement, their choice of what was studied, and the methods according to which it was undertaken. Research is not done by someone 'out there'; indeed researchers affect the process, "yet the personal tends to be carefully removed” (Widdowfield, 2000, p.200). So we sought to understand how the mobile phone or the Internet is integrated into everyday life, in other words as an embodied practice. Such an approach can offer insights for public policy, especially with the emphasis on the online delivery of public services in the UK and elsewhere, which we explore in the conclusion (Birch 2003; DTI, 2005). There are different ways we can conceive and measure emotion - in our case we looked at the scales at which technology is practised in everyday life (Hardill and Olphert, 2012). In the remaining part of the paper we examine the ways in which the emotions of the researchers and participants towards ICTs impacted upon Sus-IT at the research design stage, and during the research project.

\section{NDA and Sus-It : The emotional journey of sustaining digital engagement}

In this section we shift the focus to examine emotional events by means of a case study centring on the first author's involvement in the New Dynamics of Ageing (NDA) Research 
Programme. We first highlight the NDA programme and then examine the Sus-IT project, and the emotional journeys of older adults in sustaining digital engagement. NDA is the latest in a number of UK research council multi-disciplinary special programmes on demography and ageing (since 1997) (Hennessey and Walker, 2011). The New Dynamics of Ageing (NDA) Research Programme was established by five of the UK Research Councils ESRC, EPSRC, BBSRC, MRC and AHRC - to fund multidisciplinary research to better understand the way in which older people's lives may be changing as a result of social, economic and technical developments (http://www.newdynamics.group.shef.ac.uk/). In common with the other research programmes NDA identified people over 50 years as older people, and placed their involvement high on its agenda (Hennessey and Walker, 2011; Walker, 2007). But in a recent article Peter Lansley indicated that NDA's approach to user engagement was 'comparatively timid', with a, 'reliance on user representatives rather than a more public and ongoing exposure to wider scrutiny and comment' (2012, 27). This we will reflect on later, but that said the NDA did create the first Older People's Reference Group (OPRG) in a Research Council Programme (Walker, 2007). The OPRG played an advisory role, working alongside the Programme Director to ensure the perspectives of older people were heard and felt (ibid). There was a voice for older people, but Peter Lansley (2012) feels that this voice could have been much stronger had the OPRG been established sooner, not 'four years after the announcement of the programme [which] reinforces the impression that this was not a high priority, and that user interests can be served later rather than sooner in the research process' (ibid, 27).

The NDA programme identified a need for research using, 'participatory research methods to engage older people in the development of products, services or research...and the effective communication of users' views and priorities to those developing ICTs; the potential for 
improved outcomes of ICT systems for older people; and factors in the design of information interfaces which can reduce the risk of exclusion' (http://www.newdynamics.group.shef.ac.uk/; Walker, 2007). Writing in 2007, Alan Walker, the Director of the NDA programme commented that while there had been a significant body of research already on older adults and the uptake of digital technologies, if researchers wanted to produce findings that might contribute to the quality of life of older people or the quality of the services or products they use, then it was essential to involve them so that they can contribute their own understandings about ageing and service use which can often be far removed from those of scientists and service professionals (Walker, 2007).

The particular project we had involvement with was scoped to address the lacuna identified in the NDA call on ICT use (Damodaran and Olphert, 2010). Indeed the fundamental research question Sus-IT posed was inspired by lived reality, the challenges the late father of a member of the project team was facing as he struggled to remain digitally engaged in the face of declining eyesight, a very strong emotional impulse. So at the heart of the Sus-IT project was emotion-fused research on the challenges of sustaining ICT use by older adults. Funding was first secured in 2007 for an NDA Preparatory Network. NDA funded 11 Preparatory networks that ran between October 2006 to November 2007 (Hennessey and Walker, 2011, 63). They were funded specifically by the NDA for researchers to prepare applications for the second call for Collaborative Research Projects (CRPs) in November 2007. Each network was provided with $£ 20,000$ as seed corn to, amongst other things, work with research user groups, and form reference panels of older people; in other words to facilitate the coproduction of a research agenda. Five of these networks, including Sus-IT were funded. 
Our Preparatory Network comprised a multi-disciplinary team of social scientists and scientists (a significant number of whom were older adults) to work closer with stakeholders from all three sectors of the economy and crucially older people from local community groups to prepare the research proposal. A number of the research team knew from our own personal experience that engaging with technology in our personal lives involves emotion, so emotional impulses drew a number of the research team to the project, including the first author. She was approached to head up a ‘facilitating participation’ work package, which drew together researchers with an expertise in collaborative qualitative research in demographic ageing; engagement with practitioner networks; and participatory methods. She was particularly drawn to Sus-IT for academic and personal reasons as it offered the possibility of advancing participatory research with and for older people through focusing on a very emotive subject, integrating ICTs into her everyday life had not been easy (Hardill and Baines, 2009; Hardill and Dwyer, 2011).

Engaging with ICTs is accompanied by the experience of multiple emotions, which can have enabling and debilitating consequences for ICT users. These feelings include deep attachment experienced by those for whom ICTs have become integrated into the performance of everyday tasks, such as maintaining contact with children. ICTs also bring excitement when new ways of using the technologies are mastered. But there can be negative emotions, such as frustration caused by forgetting how to use them. Emotions relating to ICTs and cognitive judgements (such as value and risk) can also be distinguished, and there are interesting parallels with the emotions associated with the fear of crime, and engagement with ICTs. In a paper written in 1996 Hale argues that the fear of crime has consequences far beyond the deep seated sense of personal anxiety, and this concern is abstract rather than concrete. In examining crime, risk and fear Hale (1996) identifies a cognitive-affective 
dichotomy. The cognitive end of the continuum includes judgements of risk and safety while the affective end includes fear reactions - emotional reactions generated by crimes.

Sus-IT aimed to understand the challenges faced by older people using digital technologies, to identify ways to help older people to be confident and competent users of computers and other digital products, and to explore how older people's use of these technologies could be maintained in the event of declining capability and/or changed circumstances, events fused with emotion. Much previous research has focused on the differences between those who have access to the Internet and those who do not (Light, 2001; Selwyn, 2004; Warf, 2001). While long-term adoption of Internet use provides an important indicator of online engagement, however, little is known about the factors that support sustained use and those that discourage it. Sus-IT was designed to fill this gap in the literature. Sustainability of Internet use we argue represents another disparity, since there are barriers to its use that go beyond issues of access.

Sus-IT had five key objectives:

- to create an engaged community of older people who will actively participate in exploring problems and solutions related to sustaining and enhancing the use of digital technologies;

- to identify and investigate age-related change (through a study of a diverse sample of older people) and the implications for digital technology use and development

- to develop and pilot a method for automatically detecting and responding to changes in user capability ;

- to identify the learning and support needs associated with sustained and effective use of digital technologies and to pilot innovative mechanisms for meeting these needs; 
- to generate outputs to inform policy, practice, design and research, and in turn enable older people to access, creatively shape, use and adapt digital technologies to maintain and enrich their autonomy, independence and quality of life.

In order to deliver the scientific objectives Sus-IT was committed to create an engaged community of research partners to co-produce knowledge on the embodiment of ICTs, by working interactively with and for older people (Damodaran and Olphert, 2010; Hardill and Olphert, 2012). The ‘facilitating participation’ work package the first author led was designed to ensure that older people's concerns and perspectives drove and informed all stages of the research. This was achieved through building and maintaining an actively engaged pool of older people and their groups (some of whom had been part of the Preparatory Network); offering support for researchers in all work packages for participatory methods, principles and ethics; providing spaces (physical and virtual) and opportunities for older people to engage with and validate the research; and through developing a dynamic knowledge base of older peoples’ diverse interests, needs and expectations as related to ageing, quality of life and ICTs. Working interactively is time consuming (Kindon et 2007), but as the project was 39 months duration we had sufficient time to build and maintain links with groups of older people. That said the project devoured a great deal more research time than was funded by NDA, because creating a research environment sensitive to emotion and ICTs was time consuming, and members of the research team became particularly attached to the project. In the remaining part of this section we highlight some of the approaches used by the team as it sought to build an engaged pool of older people.

The methodological approach we applied was interactive rather than extractive, undertaking research with older people, rather than on them. A small group of older people acted as our 
'critical friends' providing feedback on Sus-IT publicity materials, the digital engagement study, and the participants newsletter. Based in urban and rural parts of the East Midlands, the critical friends were men and women (aged 48 - mid-80s) from community groups we engaged with in the Preparatory Network. We also ran focus groups to discuss issues such as concerns over social networking, preferred ways to learn and what frustrated them most with technology.

To meet one of the key objectives for the project we engaged with a broad range of older people, representing diversity in age, socioeconomic circumstances, ethnic background, geographical location, and ICT use. Our project coincided with Digital Switchover (from analogue to digital television signal) and concern about the implications of the push to the online delivery of public services/e-government, which generated a great deal of interest in Sus-IT. In reaching out to diverse groups of older adults a range of methods were employed through interactive sessions using images, producing a participatory video, photo diaries, and personal stories (by the research team and research participants) to stimulate discussion and debate on ICT usage (Hardill and Olphert, 2012).

We worked through 'gate-keepers' responsible, for example, for the provision of computer support, formal computer classes, University of the Third Age (U3A), Older People's Fora and community groups. We first approached gatekeepers to explain the purpose of Sus-IT, the modus operandi of the project team and to invite participation of the groups they represented in Sus-IT. The gatekeepers offered advice as to the most suitable methods of engaging with their members. As a result of these engagements some of the methods we employed did change especially relating to activities to support emotions and ICTs, 
especially overcoming fears and building confidence, such as mobile phone and IT clinics. We were surprised by the number of requests to hold such events (Hardill and Olphert, 2012).

Each interactive event was therefore planned with a specific group of older adults in mind; their needs were foremost, throughout. This led to a variety of events at which presentations about Sus-IT were given, other speakers invited (e.g. from digital outreach teams, local authorities and older people charities), and a variety of methods for capturing ICT use were employed. Moreover in response to demand from different groups we hosted special events (e.g. Festival of Social Science 2010 and 2012, Silver Surfer Day, 2010), and delivered IT taster sessions and mobile phone clinics. Our participatory research approach also encouraged some groups to be very proactive and engage in actively co-creating a research agenda with us. For example an ongoing relationship was sustained with one group in the East Midlands (membership about 200) and for four consecutive scheduled group meetings (August 2010June 2011) we worked together developing a programme of activities on older people and mobile phone use (Hardill and Olphert, 2012). We were specifically asked by the group to have sessions as part of their bi-monthly meetings that we co-produced that focused on the mobile phone, especially improving their mobile phone usage, and delivering one-to-one help via mobile phone 'clinics'.

Over this period the boundaries between researcher and researched became blurred as both the Sus-IT project team and community group members shared their mobile phone use journeys in words and images (illustrative examples in Figure 1 below), which we will return to. We shared how we (research team and research participants) had overcome ICT problems, shared information, such as the names of organisations that offered free help, or shops that had helpful members of staff. The data gathering on ICT use therefore involved 
both participant observation and self-reflection on the part of the research team, and in working so closely to our research participants we did not keep an 'emotional distance' from some of them, indeed we became attached to some, whose lives we found inspirational. We tried to capture the emotions they shared with us in our framework for understanding mobile phone (and internet) use, which was based on the scale of implication in everyday life (Figure 2, Hardill and Olphert, 2012). Shove and Pantzar (2005) argue that artefacts and forms of competence only have meaning and effect when integrated into practice, and thus that it is through the integrative work of 'doing' that elements are made animate, sustained and reproduced. When that stops fossilisation sets in. In their study of ICT use (mobile phone and the internet) in two contrasting communities in Newcastle upon Tyne, Crang and Graham (2005) found that for some people mobile phone use was episodic while for others use was pervasive, mobile phones had become an integral part of everyday life.

We have built on the work of Shove and Pantzar (2005) and Crang and Graham (2005) to develop our framework. The framework includes: first, confident ICT users; ICTs used daily forming an integral part of the architecture of everyday life; networked PCs/lap tops used with confidence to undertake a wide range of everyday tasks; such as for communicating with other people [via Skype/email]; as a source of information; for organising everyday life, including searching for information and services; in some cases mobile phones are used to access the Internet. Upgrading ICTs does not pose a challenge, indeed it is enjoyed, choosing new ICTs is almost a hobby. Confident ICT users have developed the specific skill set for Internet use, 'Internet self efficacy’ (Hargattai, 2008). Second, episodic use : sporadic use of ICTs, while some said they 'coped' using them, others were 'scared' of using them; ICTs not 'always on’; limited range of applications used, and not confidently ; and Fossilisation : as the particular focus of the Sus-IT project was on understanding the problems and 
circumstances which might cause people to ‘disengage’ or give up using ICTs, fossilisation captures the process by which mobile phone usage, for a variety of reasons, declines, to the point of complete cessation (Hardill and Olphert, 2012).

Over a period of several months the research participants shared their mobile phone and Internet use journeys, some were figured by their protagonists as 'success' stories (JS, Figure 1); in others, feelings of inadequacy surfaced, including memory problems, feeling stupid, and having no one to turn to for help (BP and AP, Figure 1). Participants shed tears, and distressing incidents and joy were shared, indicative examples of such emotions are found in Figure 1. Our research participants in different ways used Sus-IT to understand their mobile phones, and in some cases improve their mobile phone skills. For example, over this period BP demonstrated her growing confidence in using a range of mobile phone functions began texting us, one text included a note that she now had started using an ipad and was emailing and using Skype to communicate with her daughter, who had moved abroad.

The nature of the ICT struggles, and what helped individuals embed ICTs into everyday life, especially developing Internet self efficacy could inform the current emphasis on online public service delivery. ICT users are supported by the Go ON UK network (http://www.goon-uk.org/). This network is composed of 3,800 community based online centres that help people get online and make the most of online life. The centres have a local focus, and rely on local volunteers giving their time and skills to help others integrate technology into their lives. They therefore play a vital role in getting people connected but their role in sustaining digital engagement is set to increase with the push to deliver public services online. For online service delivery to work a second level digital divide based on the level of confidence with Internet use needed to be overcome (Figure 2). The importance of one-to-one help was 
stressed by BP (Figure1). But one-to-one is not always enough, as with AP (Figure 1). AP attended a specialist course that helped to get her started using the Internet, and confirmed to her that the Internet is relevant to her everyday life, but for her to be able to use the computer at home - unaided - she needs a slight adaption to be made.

\section{Concluding comments}

In this paper we have highlighted how engaging with emotions is enabling social scientists to explore social relations as they are lived and experienced. We have focused specifically on emotional and embodied knowledge by drawing upon a research project forming part of the NDA research programme, a key tenet of which being the stipulation that research teams coproduce knowledge with and for older adults. Such a collaborative research project led to a research approach that sought solutions, not just the identification of barriers, and the delivery of practical impacts or benefits, including policy recommendations.

The Sus-IT research agenda was identified by an emotive impulse, the challenges the late father of a member of the team was facing as he struggled to remain digitally engaged in the face of declining eyesight. The project examined the ways in which the materialities of ICT (and new technology more broadly) "increasingly affects/infects the minutiae of everyday life and corporeal existence” (Grosz, 1994, p. 48; cited in Barratt, 2012, p. 46). Through examining ICT use as an embodied practice the boundaries between researcher and researched became blurred and a second level digital divide based on the scale of implication of ICTs in everyday life was identified. In partial recognition of Latham's (2003) now oftencited critique of those “now canonical techniques” (p. 1998) - in-depth interviews, focus groups and participant observation - a range of methods were used in order to access and relate the challenges people face in sustaining digital engagement. Using ICTs is about 
developing and then maintaining a level of proficiency to use ICTs for a range of everyday tasks. ICTs can help people to continue to shop when confined to the home, overcome fears to move outside the house, or maintain social contact with family and friends (Figure 2, Hardill and Olphert, 2012).

To date emotive awareness has been neglected in evidence based policy, which has a particular resonance in times of economic austerity because of the need for public services to be delivered in different ways. When we began our project in 2009 in the UK New Labour had a commitment to the online delivery of public services or e-government (DTI, 2005). As White and Selwyn (2013) state “... policy interventions aimed at both increasing and widening Internet access and use will be ineffective unless the social, rather than technological, basis of inequalities in access and use are recognized.” (p. 1). But in 2010 upon taking power, the Coalition Government in the UK abolished the Delivery Unit, which had a broad understanding of evidence (Barber, 2007) and undertook a strategic review of egovernment and the online delivery of public services. As a result of that review responsibility for it moved from the Department of Work and Pensions to the Cabinet Office, so it has moved to the heart of Government. Speaking in 2011, Cabinet Office Minister Francis Maude said the Coalition was, 'determined to offer world class digital products that meet people's needs and offer better value for taxpayers' money' (http://digital.cabinetoffice.gov.uk/2011/12/08/new-home-for-gds/). But for e-government to succeed, and be a realistic option for those who need access to public services, it is not just about getting people connected to the Internet, it is about helping them develop Internet self efficacy (Hargattai, 2008) and stay connected. So a second digital divide has to be tackled, helping episodic ICT users develop a skill set to use the Internet with confidence, so as to be able to access public services online. 


\section{Acknowledgements}

This paper draws on research funded by the New Dynamics of Ageing programme, Sustaining IT use by older people to promote autonomy and independence (Sus-IT) lead by Leela Damodaran and Wendy Olphert (RES-353-25-0008). We wish to acknowledge the contribution of the Sus-IT team, in particular L. Damadoran, W. Olphert, J Sandhu, S Keith and M Heeley, and our research participants. The views expressed here are those of the authors alone. We are grateful to the referees and Jon Bannister for their helpful comments

\section{References}

Anderson, B. and Harrison, P. (2006) Questioning affect and emotion, Area, 38, 333-5

Anderson, B. and Harrison, P. (2010) Taking-Place: Non-Representational Theories and Geography Aldershot: Ashgate

Anderson, K. and Smith, SJ. (2001) Editorial: emotional geographies, Transactions of the Institute of British Geographers 26 (1), 7-10

Askins, K. (2009) 'That's just what I do': placing emotion in academic activism, Emotion, Space and Society 2 (1), 4-13

Bannister and O’Sullivan - this issue

Barber, M. 2007. Instruction to Deliver (London, Politico's). 
Barratt, P (2012) 'My magic cam': a more-than-representational account of the climbing assemblage, Area, 44(1), 46-53

Bennett, K. (2004) Emotionally intelligent research Area 26(4), 414-22

Birch, D. (2003) Local e-Government: A survey of local authorities (Office of the Deputy Prime Minister, London)

Bondi, L. (2005) The place of emotions in research: from partitioning emotion and reason to the emotional dynamics of research relationships, In Emotional Geographies (Eds J. Davidson, L. Bondi, and M. Smith, Ashgate, Aldershot, pp. 231-46

Brown, G. and Pickerill, J. (2009) Space for emotion in the spaces of activism, Emotion, Space and Society 2 (1), 24-35

Crang, M. and Graham, S.D.N. (2005) Multispeed cities and the logistics of living in the Information Age Project report ESRC Swindon accessed 24 April 2011 Durham Research online (http://dro.dur.ac.uk)

Damodaran, L. and Olphert, C.W. (2010) Sustaining Digital Engagement: Some Emerging Issues. Proceedings of Digital Futures 2010, Nottingham. 10-12 October 2010. Available at: https://www.horizon.ac.uk/images/stories/f50-Damodaran.pdf 
Davidson, J., Bondi, L. and Smith, M. (eds) (2005) Emotional Geographies Aldershot: Ashgate

Davidson, J. and Milligan, C. (2004) Embodying emotion sensing space: introducing emotional geographies, Social and Cultural Geography 5 (4), 523-532

DTI (2005) Connecting the UK:the Digital Strategy HMSO, London

Grosz, E (1994) Volatile bodies: toward a corporeal feminism, London: Allen \& Unwin

Hale, C. (1996) Fear of crime: a review of the literature International Review of Victomology 4, 79-150

Hardill, I. and Baines, S. (2009) Personal reflections on Knowledge Transfer and changing UK research priorities $21^{\text {st }}$ Century Society 3:1, 81-94

Hardill, I. and Dwyer, P. (2011)Growing old in rural England: some challenges of delivering village services in the mixed economy of welfare paper Journal of Social Policy, 40,1,157-72

Hardill I and Olphert W (2012) Staying connected: Exploring mobile phone use amongst older adults in the UK Geoforum

Hargattai E (2008) Whose Space? Differences Among Users and Non-Users of Social Network Sites Journal of Computer-Mediated Communication 13, 276-297

Hennessey, C. H. and Walker, A. (2011) Promoting multi-disciplinary and inter-disciplinary ageing research in the United Kingdom Ageing and Society 31, 52-69 
Horton, J. and Kraftl, P. (2006) Not just growing up, but going on: materials, spacings, bodies, situations, Children’s Geographies 4 (3), 259-276

Jones, O. (2005) 'An ecology of emotion, memory, self and landscape' In Emotional Geographies (Eds J. Davidson, L. Bondi, and M. Smith, Ashgate, Aldershot, pp. 205-218

Kindon, S., Pain, R. And Kesby, M. (2007) Participatory action research approaches and methods: connecting people, participation and place London: Routledge

Latham, A. (2003) Research, performance and doing human geography: some reflections on the diary-photograph, diary-interview method, Environment and Planning A 35, 1993-2017

Lansley, P. (2012) Multi-disciplinarity, user engagement and the design of special programmes of ageing research in the United Kingdom Ageing and Society doi: 10.1017/S0144686X12000190

Light, J. (2001). Rethinking the digital divide. Harvard Educational Review, 71(4), 709-734. Retrieved from http://hepg.metapress.com/content/342X36742J2W4Q82

Longhurst, R., Ho, E., and Johnston, L. (2008) Using 'the body' as an 'instrument of research': kinch'i and pavlova Area, 40(2), 208-17

Lorimer, H. (2008) Cultural geography: non-representational conditions and concerns, Progress in Human Geography 32 (4), 551-559 
Lorimer, H. (2005) Cultural geography: the business of being 'more-than-representational', Progress in Human Geography 29 (1), 83-94

McCormack, D. (2003) An event of geographical ethics in spaces of affect. Transactions of the Institute of British Geographers 28 (4), 488-507

Pile, S. (2010) Emotions and affect in recent human geography, Transactions of the Institute of British Geographers 35 (1), 5-20

Pini, B., Mayes, R. and McDonald, P. (2010) The emotional geography of a mine closure: a study of the Ravensthorpe nickel mine in Western Australia, Social and Cultural Geography $11(6), 559-574$

Pink, S. (2009) Sensory Ethnography ( Sage, London)

Rose, G., Degen, M. and Basdas, B. (2010) More on 'big things': building events and feelings, Transactions of the Institute of British Geographers 35 (3), 334-349

Selwyn, N. (2004). Reconsidering political and popular understandings of the digital divide. New Media \& Society, 6(3), 341-362. Retrieved from http://nms.sagepub.com/content/6/3/341.abstract

Shove, E. and Pantzar, M. (2005) Fossilisation Ethnologia Europaea - Journal of European Ethnology, 35, 59-63.

Simpson, P. (2011) 'So, as you can see...': some reflections on the utility of video methodologies in the study of embodied practices, 43 (3), 343-352

Sin, C.H. (2003) Interviewing in 'place': the socio-spatial construction of interview data. Area 35 (3), 305-312

Thein, D. (2005) After or beyond feeling? A consideration of affect and emotion in geography Area 37 (4), 450-454 
Thrift, N. (2004) Intensities of feeling: towards a spatial politics of affect, Geografiska Annaler 86B, 57-78.

Walker, A. (2007) Why involve older people in research? Age and Ageing 36, 481-83.

Warf, B. (2001). Segueways into cyberspace: Multiple geographies of the digital divide. Environment and Planning B: Planning and Design, 28, 3-19.

White, P., \& Selwyn, N. (2013). Moving On-Line? An analysis of patterns of adult Internet use in the UK, 2002-2010. Information, Communication \& Society, 16 (1), 1-27.

Widdowfield, R (2000) The place of emotions in academic research, Area, 32(2), pp. 199208

\footnotetext{
'We use the term ICT to broadly refer to the integration of telecommunications (telephone lines and wireless signals), computers, middleware, software, storage, and audio-visual systems, which enable users to create, access, store, transmit, and manipulate information.
} 